\title{
Reacções químicas que produzem luz
}

A quimioluminescência, conversã̃o de energia química em estados electrónicos excitados, tem fascinado os estudantes e professores durante décadas. A emissão de luz por várias plantas e animais (bioluminescência, um tipo específico de quimioluminescência) é conhecida desde os primórdios da humanidade, mas os primeiros registos de sistemas quimioluminescentes na literatura cientifica datam do último quarto do séc. XIX [1]. O séc. XX viu crescer a investigação nesta área, com a descoberta de muitos sistemas quimioluminescentes. Os sistemas mais comuns envolvem o luminol, ésteres do ácido oxálico, lucigenina, tris(bipiridil)ruténio(II) ou luciferina. A reacção química que produz quimioluminescência nesta demonstração [2] envolve a redução do tris(2,2'-bipiridil)ruténio(II) $\left(\mathrm{Ru}(\text { bpy })_{3}{ }^{2+}\right)$ e do persulfato
$\left(\mathrm{S}_{2} \mathrm{O}_{8}{ }^{2}\right)$ pelo magnésio $(\mathrm{Mg})$ :

$$
\begin{aligned}
& \mathrm{Ru}(\text { bpy })_{3}{ }^{2+}+\mathrm{e}^{-} \rightarrow \mathrm{Ru}(\text { bpy })_{3}{ }^{+} \\
& \mathrm{S}_{2} \mathrm{O}_{8}{ }^{2-}+\mathrm{e}^{-} \rightarrow \mathrm{SO}_{4}{ }^{2-}+\mathrm{SO}_{4}{ }^{-}
\end{aligned}
$$

A produção do complexo num estado electrónico excitado ocorre através de uma reacção de transferência electrónica envolvendo o oxidante forte $\mathrm{SO}_{4}$, produzido na reacção (2):

$$
\mathrm{Ru}(\mathrm{bpy})_{3}{ }^{+}+\mathrm{SO}_{4}{ }^{-}{ }^{\star} \mathrm{Ru}(\mathrm{bpy})_{3}{ }^{2+}
$$

onde * $\mathrm{Ru}(\mathrm{bpy})_{3}{ }^{2+}$ é a espécie de estado excitado responsável pela emissão de luz:

$$
{ }^{*} \mathrm{Ru}(\mathrm{bpy})_{3}{ }^{2+} \rightarrow \mathrm{Ru}(\mathrm{bpy})_{3}{ }^{2+}+h v(610 \mathrm{~nm})
$$

\section{Interesse da Actividade}

Apesar de espectacular, o tema da quimioluminescência é raras vezes abordado com alguma profundidade nos cursos de Química, o que só por si justifica esta actividade. Informação de carácter geral acerca da quimioluminescência [3-7] e acerca dos detalhes mecanísticos envolvidos nas reacções mais conhecidas [8] estão hoje disponiveis

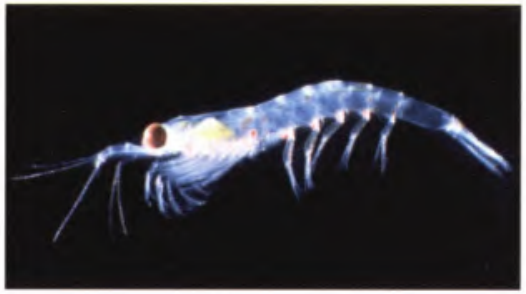

figura 1 Euphauria pacifica (tamanho aprox. $2 \mathrm{~cm}$ )

mecanismos dessas reacções, b) numa enorme variedade de aplicações analíticas (análise clínica de moléculas biológicas como o ADN e anticorpos), c) sob a forma de bastonetes luminosos usados em iluminação subaquática, e d) também na indústria da moda sob a forma de pulseiras e colares luminosos. Vários exemplos dessas aplicações, bem como demonstrações e informação em abundância na literatura.

Longe de ser uma mera curiosidade, a quimioluminescência tem encontrado aplicações muito variadas. Tem sido utilizada: a) para seguir reacções químicas e elucidar a energética e os sobre quimioluminescência e bioluminescência pode ser encontrada em http://www.shsu.edu/chemilumdir/chemisites. html.

\section{Acerca da Actividade}

Os compostos utilizados nesta actividade estão disponiveis comercialmente a um preço razoável. Alguns cuidados devem ser postos no manuseamente dos reagentes: o $\left[\mathrm{Ru}(\mathrm{bpy})_{3}\right] \mathrm{Cl}_{2}$ é um complexo de um metal pesado e a sua toxicidade não é conhecida, o persulfato de amónio é um oxidante forte e o ace- tonitrilo é irritante para os olhos, pele e vias respiratórias. Aconselha-se que a preparação das soluçōes e a demonstração seja feita utilizando óculos e luvas, em local arejado e longe de qualquer chama, devido à pequena produção de hidrogénio pelo Mg.chm_tgcl

\section{Respostas}

2) Hidrogénio. $2 \mathrm{H}^{+}(\mathrm{aq})+\mathrm{Mg}(\mathrm{s}) \rightarrow \mathrm{H}_{2}(\mathrm{~g})+\mathrm{Mg}^{2+}(\mathrm{aq})$

3) $-188 \mathrm{~kJ} \mathrm{~mol}^{-1}$

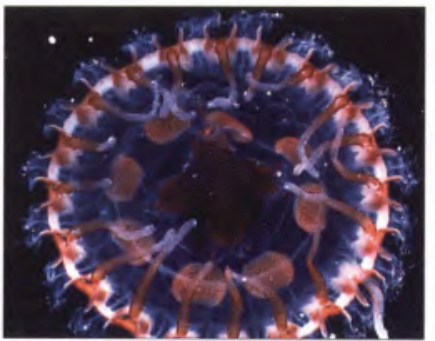

figura 2 Atolla vanhoeffi $(3 \mathrm{~cm})$. As fotos de espécies marinhas bioluminescentes foram tiradas de http://lifesci. ucsb. edu

\section{Referências}

1. Gundermann, K.-D., McCapra, F. "Chemiluminescence in Organic Chemistry", Springer-Verlag, Berlin, 1987.

2. Bolton, E. Richter, M. M. J. Chem. Educ., 2001, 78, 47

3. Gunderman, K. D. Angew. Chem. Int. Ed. Engl. 1965, 4, 566.

\section{McCapra, F. Quart. Rev. (London) $1966,485$. \\ 5. Haas, J. W. J. Chem. Educ. 1967, 44, 396 \\ 6. Seybold, P. G. Chemistry 1973, 46, 6.}

7. Cormier, M. J.; Hercules, D. M.; Lee, J., Eds. "Chemiluminescence and Bioluminescence"; Plenum Press: New York, 1973.

8. Schuster, G. Acc. Chem. Res. 1979, 12, 366. 